\section{Contemporary Problems in Science Jobs (Second Edition) Part 2: What Good CVs Look Like! (The Science Career Path Reality)}

\author{
Arthur E. Sowers, Ph.D.
}

My 9 years in industry, 5 years in academia, and 4 years as a postdoc tell me this about getting a regular (tenure-track) faculty appointment:

On a very simple level, one who wishes to be in lofty pursuits (an academic position at a research institution, where the goals are noble and the intellectual rewards are pure and at least some people respect you) would follow this conventional-wisdom paradigm:

First get a Ph.D (or MD/Ph.D), next get a postdoc, and then get an assistant "prof." position. After that things are supposed to be more or less automatic. Right? BZZZZ! Wrong!

In 1977 I received my Ph.D and did a postdoc (1978-1981) and then began to learn how all of this really worked.

The situation back then was, as it is today, that there were about 200-300 applications per entry level (assistant prof.) tenure-track slot. I then observed, while doing a postdoc at UNC, School of Medicine, Chapel Hill, was that the CVs that rose to the top had, or tended to have, certain "obvious" characteristics - as follows:

(i) Ivy league, big 10 or big 20 institution names for the Ph.D.

(-) Places that are "exotic" for a postdoc to be from (e.g., Rockefeller, Max Plank, Cold Spring Harbor, in addition to the usual).

(-) Publications (about 2-3 per year) in Science, Nature, Cell, PNAS, etc.

(1) An existing, transferable grant (usually $\mathrm{NIH}$, and $\$ 60 \mathrm{~K}$ plus for indirect costs).

(-) A background that fits in with the advertised position specification.

(-) A specialization that could support you, perhaps with existing faculty, as a co-investigator on future grant proposals (such arrangements can be great since you have enthusiastic "partners" to help with witing, but can be bad if the other guys let you do most of the work and then take the credit)

(-) Per Ken Steele: "The homeboy factor is stronger than many imagine." Some in the department may be from the same region, school, etc. and this is what they look for, or notice, in an applicant. As a result, true merit may sometimes be lost in the dust. In this regard, one might look in college and university catalogs and consider where faculty received their degrees. Ivy league schools tend to recruit from other ivy leagues while smaller, elite colleges often recruit from prestige schools (e.g., ivy league), and state schools from all institutions. Teaching institutions often recruit for teaching promise and experience, and research competence may be of little interest.

(.) Smaller, elite colleges tend not to be research career focused. Rather, they will be more concerned with the commitment one makes towards teaching - plus one's interest in small college ambiance and culture. In other words, how you look as a researcher may not matter much, but if you have no teaching experience AND don't have anything on your CV or cover letter (or the rest of your application package) that really shows an interest in teaching, then your $\mathrm{CV}$ is going to end up in the trash.

There are several anti-selection characteristics, too:

(:) Background not in "square" with job description (e.g. an entomologist applying for a job in an anatomy department)

(2) Anybody higher than associate professor (including chairmen), people who were only at teaching institutions, and the more elderly quickly fell off the list.

(8) Anybody who had been assistant professor at 2 or more other institutions. This is because the people on the selection committee might figure that there is something wrong with you because you did not get tenure.

(2) Obscure, short papers in trashy, obscure journals (especially if there were, eg., 10 or more per year).
(-) Anybody who followed a non-ideal career path. For example, a truck driver for ten years goes back to school for a Ph.D, a woman who steps off the path to be mother for 2-3 years (yeah, I'm sorry but some see that gap as a blemish on a career trajectory).

(2) People who have dirt on their name. Bad gossip, whether true or false certain political problems (10-20 years ago you might have had trouble if you were very left wing - you would not get a job in science). Today, it may not be important.

(2) Thanks to an associate for the following. I HAVE heard about it before but previously left it out because I did not want to stigmatize anyone. But, we ought to tell-it-like-it-is. "Postdocs" at government labs may not be a good idea for your career. Yes, academia generally does not respect time spent at such places and that needs to be considered even though the pay might be greater. My associate says in his private e-mail to me that "I'm one of those guys in his $50 \mathrm{~s}$ - and its hard to believe that I might not make it in this career to retirement." My associate continues to advise that "we may be committing professional suicide because we are not in a glamour area of science and we are not at a fancy institution."

IN OTHER WORDS, MOST OF US HAVE A WINDOW OF OPPORTUNITY AND IF WE MISS IT, THEN WE MAY BE MESSED UP FOR LIFE.

People who are selected as candidates for a position usually have to give a seminar and spend at least a day at the institution. The seminar has to be at a quality level that I would call the "upper half" category. To fall off the short list, you had to give a really goofy or bad seminar (and this happened, too). In contrast, at a teaching institution, your seminar or (short demonstration of presentation abilities) will be more scrutinized for delivery, content, collegiality, and style.

Some real-life but non-obvious factors might play a significant role in a person being offered a position. However, these factors may never become public knowledge. Some are:

$\odot$ Real programmatic considerations,

(-) Absolutely astounding letters of recommendation from luminaries (one prof at Berkeley told me this: he considered himself average, but he got the job because of an exceptional recommendation letter),

- Operation in the background of a personal connection or preference of some kind (some people call this politics and it does happen).

(-) An agenda. For example, there may be an actual preference to hire a minority or a female, or a science subdiscipline (eg. HIV science, extracellular matrix, biotechnology, etc., or some other "hot topic").

Some of these non-obvious factors may actually dominate the decision making to the point of relegating the obvious factors out of the question. Anti-discrimination laws help prevent some of the outlandish anti-selection factor processes, but they don't seem to have much effect until someone already hired is released or denied tenure or tenure removed (see Chronicle of Higher Education all year long on this). I think not much else has changed since the mid 1970 s except the much greater competition for grant funding.

This is what you have to measure yourself against.

What was the most intimidating CV I ever saw? It was just two pages long! The top half of the first page had the education. The bottom half of the first page had a list of special awards. The second page just gave numbers of journal papers, books, and chapters, not the titles and citations. The second page also had a story in which the individual said how many Ph.Ds he graduated (it was around 40-50 if I recall correctly), how many of those went on into tenure track positions (it was most of them) and how many of those were promoted with tenure (almost of them). In other words it was an awesome success story. This guy not only did get the job, but he also got the whole floor of a building. I am sure the rest of the "package" (i.e. start up money, etc.) was also impressive.

There is also a line of thinking that is developing. Departments are not going to play a significant role as much as centers of excellence (containing 10-20 or more people). Such centers of excellence will have a "life cycle" of 12-15 years and then be disbanded.

Try not to use the above material to gauge yourself in an absolute way, because there are often exceptions to the rule in real life. But do use it as a guide. 


\section{Improve your image
with a Gatan MultiScan CCD camera}

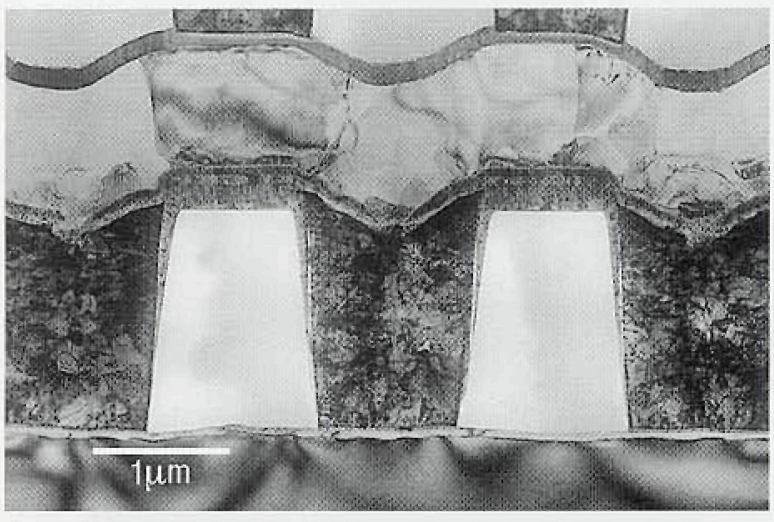

Cross-section through a Si-based IC device showing various W plugs (specimen prepared by Dr. P. Ling, Amer).

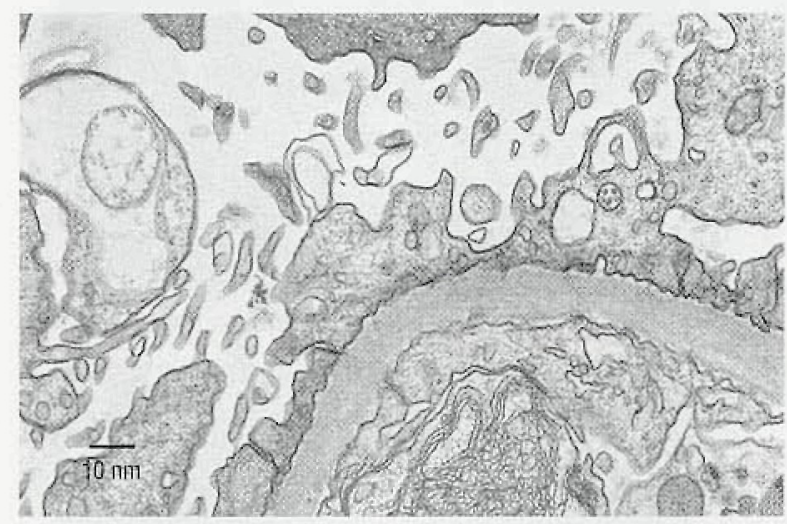

Amyloidosis in kidney.
Gatan CCD cameras outperform photographic film for linearity, sensitivity and dynamic range. The result: better TEM images.

Gatan MultiScan (MSC ${ }^{\mathrm{TM}}$ ) CCD cameras are available for both wide angle $35 \mathrm{~mm}$ or high resolution bottom-mount applications. Here are a few unique features of Gatan CCD cameras.

Fast sample survey. The ability to collect five frames per second allows you to use the MSC to select and optimize your viewing area.

Outperforms film. Our CCD cameras demonstrate linearity of better than $1 \%$ over the entire dynamic range of $16,000: 1$.

Equipped with a high sensitivity phosphor, MSC cameras can detect single $100 \mathrm{kV}$ electrons.

Increase productivity, lower costs. Real-time image viewing allows easy optimization of imaging conditions and reduces darkroom costs.

Gatan Low Dose Imaging and DigitalMontage ${ }^{\text {th }}$ allow you to focus and stigmate on an isolated region of the sample, and then to rapidly acquire many images using spot scan. In DigitalMontage you specify the array size and percent overlap and the new algorithms automatically montage the digital images to near perfection.

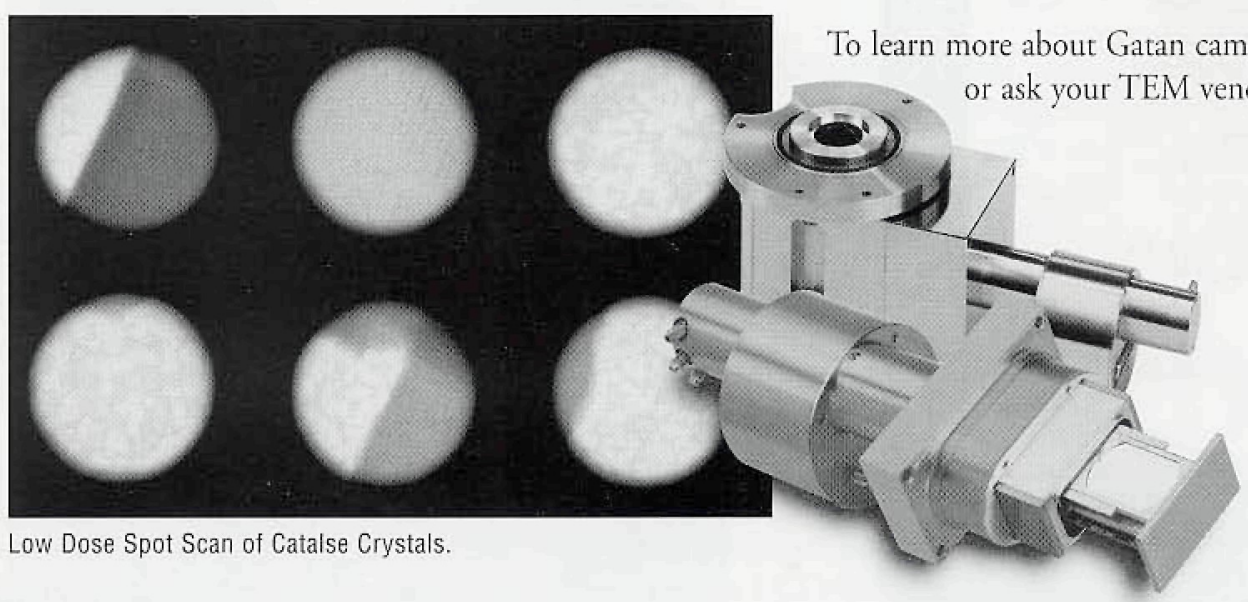

The Gatan bottom-mount (background) and wide-angle (foreground) MSC cameras.

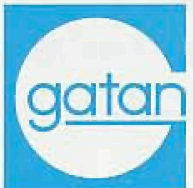

Gatan Inc.

6678 Owens Drive

Pleasanton, CA 94588

USA

Tel 5104630200

Fax 5104630204
Gatan Online

http:/www.gatan.com

info@gatan.com

help@gatan.com
Gatan Inc.

780 Commonwealth Driwe

Warrendale, PA 15086

USA

Tel 4127765260

Fax 4127763360
Gatan GmbH Ingolstädter Straße 40 D-80807 München Germany

Tel (089) 352374

Fax (089) 3591642
Gatan Led.

17 Medlicost Close Oakley Hay, Corby NN $189 \mathrm{EY}, \mathrm{UK}$

Tel $(01536) 743150$

Fax $(01536) 743154$ 